The effects of service quality dimensions and passenger characteristics on passenger's overall satisfaction with an airport

\author{
George C. L. Bezerra \\ University of Coimbra \\ School of Economics \\ Av. Dias da Silva 165 \\ 3004-512 Coimbra - Portugal \\ Tel: +351239790588 \\ Email: george.bezerra@student.uc.pt \\ Carlos F. Gomes \\ University of Coimbra \\ School of Economics \\ ISR-Institute of Systems and Robotics \\ Av. Dias da Silva 165 \\ 3004-512 Coimbra - Portugal \\ Tel: +351 239790588 \\ Email: cfgomes@fe.uc.pt
}

This is a post-print (i.e. final draft post-refereeing) of an article published in Journal of Air Transport Management, available online at:

https://doi.org/10.1016/i.jairtraman.2015.03.001.

Citation: Bezerra, G.C.L., \& Gomes, C.F. (2015) "The effects of service quality dimensions and passenger characteristics on passenger's overall satisfaction with an airport", Journal of Air Transport Management, 44-45, pp. 77-

81, http://dx.doi.org/10.1016/i.jairtraman.2015.03.001. 
Bezerra, G.C.L., \& Gomes, C.F. (2015) "The effects of service quality dimensions and passenger characteristics on passenger's overall satisfaction with an airport", Journal of Air Transport Management, 44-45, pp. 7781, http://dx.doi.org/10.1016/j.jairtraman.2015.03.001.

\title{
The effects of service quality dimensions and passenger characteristics on passenger's overall satisfaction with an airport
}

\begin{abstract}
:
The objective of this paper is twofold. First, to identify service quality dimensions related to airports. Second, to examine the effects of those dimensions on passenger's overall satisfaction with an airport together with variables related to passenger characteristics. Data from an extensive survey applied in a main Brazilian international airport were used. Exploratory factor analysis was applied to extract dimensions of airport service quality as perceived by the passengers. The effects on the overall satisfaction level were estimated using a probabilistic approach. Findings underline implications regarding the use of meaningful service dimensions instead of a large set of variables as predictors of passenger satisfaction. Moreover, the study stresses the need for considering how passenger characteristics may be related to different perceived levels of service quality.
\end{abstract}

Keywords: Airport service quality; Passenger satisfaction; Service quality dimensions. 
Bezerra, G.C.L., \& Gomes, C.F. (2015) "The effects of service quality dimensions and passenger characteristics on passenger's overall satisfaction with an airport", Journal of Air Transport Management, 44-45, pp. 77-

\section{INTRODUCTION}

Since service is not a physical item, but an experience, service quality is strictly linked to customer satisfaction. Actually, customer's perception of quality is an antecedent of his/her satisfaction level with the service (Brady and Cronin, 2001; Falk et al., 2010).

Service quality and passenger satisfaction are subjects of high interest within the airport industry. Surveys have been systematically carried out by international agencies (ACl, 2013; IATA, 2012), as well as several ad hoc initiatives by other organizations and airports (Fodness and Murray, 2007; Zidarova and Zografos, 2011). Due to increasing traffic and changes in the air transport market, it has become more important for airport managers to measure, analyse and extract relevant information regarding passengers' perception on Airport Service Quality (ASQ).

As result of a cognitive process, the perceived service quality is not only subjective, but also context dependent and will likely vary according to several factors (Wilson et al., 2012). Passenger behaviour and expectations regarding the airport experience are dependent on the type of traveller, trip purpose and other context-related aspects (Fodness and Murray, 2007). Thus, the attributes for measuring ASQ should reflect the evaluation problem and the service environment investigated (George et al., 2013; Yeh and Kuo, 2003).

Unlike other sectors, the airport industry is still in search of a comprehensive framework for the antecedents of ASQ (Fodness and Murray, 2007; Jeon and Kim, 2012; Zidarova and Zografos, 2011). Moreover, the influence of the different factors related to airport service on passenger satisfaction is still not entirely researched (Bogicevic et al., 2013). 
Bezerra, G.C.L., \& Gomes, C.F. (2015) "The effects of service quality dimensions and passenger characteristics on passenger's overall satisfaction with an airport", Journal of Air Transport Management, 44-45, pp. 7781, http://dx.doi.org/10.1016/j.jairtraman.2015.03.001.

In this context, the objective of this paper is twofold. First, to identify service quality dimensions related to airport services. Second, to examine the effects of those dimensions on passenger's overall satisfaction together with variables related to passenger characteristics.

\section{METHODOLOGY}

Data related to Guarulhos International Airport, in Brazil, were obtained from an extensive survey coordinated by the Brazilian government, from January to December 2013. Departing passengers of international commercial flights were approached at the departure lounge during peak hours in order to take their opinions at a moment of high demand (SAC, 2014). After missing value treatment, final sample comprised 1568 cases (see Appendix A).

The survey included attributes related to services/processes and airport facilities. The items were aligned with industry best practices (ACl, 2012; Hazel et al., 2011; IATA, 2012) and previous studies (Bandeira et al., 2014; Correia et al., 2008a; Eboli and Mazzulla, 2009; George et al., 2013; Seyanont, 2012; Yeh and Kuo, 2003). Passengers were asked to rate each item according to an ordinal 5-point scale.

This study focused on attributes related to the passenger terminal. In the first phase of data analysis, exploratory factor analysis (EFA) extracted underlying service quality dimensions as perceived by the passengers. Component analysis method and varimax orthogonal rotation procedure were utilized (Hair et al., 2009). The loadings greater than 0.5 were considered significant. 
Bezerra, G.C.L., \& Gomes, C.F. (2015) "The effects of service quality dimensions and passenger characteristics on passenger's overall satisfaction with an airport", Journal of Air Transport Management, 44-45, pp. 7781, http://dx.doi.org/10.1016/j.jairtraman.2015.03.001.

In the second phase, an ordinal logistic regression model was estimated to examine the effects of the service dimensions and passenger characteristics on passenger's overall satisfaction with the airport. The variables for representing the service quality dimensions were created by averaging the scores for the items that loaded on each factor (Hair et al., 2009) (See Table 1). The variables for passenger characteristics are presented in Appendix A.

[Insert Table 1 here]

Whereas the probabilistic approach for modelling relationships in service quality is present in Marketing (Akinci et al., 2007) and Tourism and Hospitality research (Thrane, 2005), it has been scarcely used within the airport context (Carstens and Heyns, 2012; Eboli and Mazzulla, 2009; Gkritza et al., 2006). There are advantages in using probabilistic models when dealing with ordinal scales, categorical variables, and in cases where data do not satisfy linear regression assumptions (Hair et al., 2009; Akinci et al., 2007).

The logistic model takes the log of the odds that the passenger rates a category $j$ or lower against one category higher than $j$ (what is called Logit). Thus, the estimated parameters express a linear relationship between the Logit and the explanatory variables. It assumes that the regression coefficients are equal to all categories, according to the equation in Appendix B (Gujarati and Porter, 2011).

Since the estimated coefficients express the relationship between Logit and explanatory variables, their first interpretation points to the direction of the effect on the probability that the passenger assigns a higher level of satisfaction instead of a lower level. Additionally, the 
Bezerra, G.C.L., \& Gomes, C.F. (2015) "The effects of service quality dimensions and passenger characteristics on passenger's overall satisfaction with an airport", Journal of Air Transport Management, 44-45, pp. 7781, http://dx.doi.org/10.1016/j.jairtraman.2015.03.001.

exponentiated coefficient can be used to evaluate the effect in terms of percentage change in odds: Percentage change in odds $=($ Exponentiated coefficient -1$) \times 100$.

Given the nonlinear nature of logistic function, a model was estimated by the maximum likelihood method (Hair et al., 2009). Backward elimination was used as an alternative for model specification and a coefficient significance $<0.05$ as elimination criterion.

\section{RESULTS AND DISCUSSION}

\subsection{Factor analysis results}

Data presented good level of adequacy, with $\mathrm{KMO}$ value of 0.883 and significance level $<0.01$ for the Bartlett's test of sphericity. The Measure of Sampling Adequacy (MSA) had all values higher than 0.7.

Only the variables with communalities above 0.5 were retained (Hair et al., 2009), consequently two variables related to the passport control process were excluded.1 A solution with seven factors representing $67.15 \%$ of total variance was obtained (Table 1 ). The internal consistency was confirmed by Cronbach's Alpha (Hair et al., 2009).

\subsection{Regression analysis}

Regression results presented six dimensions and two passenger characteristic variables with statistical significance at 0.05 level (Table 2). 
Bezerra, G.C.L., \& Gomes, C.F. (2015) "The effects of service quality dimensions and passenger characteristics on passenger's overall satisfaction with an airport", Journal of Air Transport Management, 44-45, pp. 77-

[Insert Table 2 here]

The model presented global significance according to the Likelihood-Ratio. Pseudo$\mathrm{R}^{2}$ measures provided indication of model explanatory power while considered along with the number of correctly predicted cases (given by Count $R^{2}$ measure) (Gujarati and Porter, 2011). According to the test of parallel lines, the model was fitted with logistic function at a 0.05 significance level.

The following general estimated equation was obtained: Logit $=a_{j}-\left[+0.241\left(C h k_{i}\right)+0.310\left(\operatorname{Sec}_{i}\right)\right.$ $-0.276\left(\right.$ Con $\left._{i}\right)+2.214\left(A m b_{i}\right)+0.592\left(\right.$ Bas $\left._{i}\right)+0.634\left(\operatorname{Prc}_{i}\right)+0.189\left(\right.$ Arr $\left._{i}\right)-0.171\left(\right.$ Frq $\left.\left._{i}\right)\right]$. Where $a_{1}=$ $6.291, a_{2}=9.475, a_{3}=12.460$, and $a_{4}=16.167$ are the values for the four intercepts $a_{j}$.

\subsubsection{Direction of the effects}

According to the results, a passenger is more likely to assign higher ratings for overall satisfaction with the airport the higher his/her level of satisfaction regarding the dimensions "Check-in", "Security", "Ambience", "Basic facilities", and "Prices". In contrast, it seems that the higher his/her satisfaction with the "Convenience" dimension, the less likely the passenger is to assign a higher rating for overall satisfaction.

The non-significant effect of "Mobility" may suggest that the attributes in this dimension may be generally a minor concern for departing passengers at international hubs of lower complexity, as is the case of Guarulhos Airport (Correia et al., 2008b).

Regarding the passenger characteristics, nationality, gender, trip purpose and mobility condition presented no significant effect. The finding that frequent flyers are less likely to 
Bezerra, G.C.L., \& Gomes, C.F. (2015) "The effects of service quality dimensions and passenger characteristics on passenger's overall satisfaction with an airport", Journal of Air Transport Management, 44-45, pp. 7781, http://dx.doi.org/10.1016/j.jairtraman.2015.03.001.

present higher levels of satisfaction, because of the negative coefficient, is consistent with previous studies (Pakdil and Aydın, 2007; Park, 2010).

The positive effect of "Earliness of arrival" suggests that the earlier the passenger arrives at the airport, the more likely he/she is to present a higher overall satisfaction. This may be associated with the fact that passenger's level of stress is related to the amount of time available for complying with the required checkpoints. Previous research has found passengers are more stressed before check-in and immediately before boarding (Crawford and Melewar, 2003). Also, the total amount of time passengers spend at the airport is often much greater than their processing time (Caves and Pickard, 2000). Thus, passengers who arrived early are more likely to be relaxed at the checkpoints, allowing them to avoid larger lines.

The negative effect of "Convenience" is particularly interesting. This finding may be explained by the relationships among passenger consumer behaviour, the earliness of arrival at the airport, and the nature of "Convenience" as satisfier or dissatisfier factor.

Airports are unique retail environments due to psychological issues related to the travel process. Hence, passengers experience feelings of anxiety, stress and excitement that might make them react in unusual ways comparing to conventional shopping centers (Crawford and Melewar, 2003; Omar and Kent, 2001). Since the passenger is not at the airport for the primary purpose of shopping, convenience and pastime are main motivations for purchasing (Omar and Kent, 2001). 
Bezerra, G.C.L., \& Gomes, C.F. (2015) "The effects of service quality dimensions and passenger characteristics on passenger's overall satisfaction with an airport", Journal of Air Transport Management, 44-45, pp. 7781, http://dx.doi.org/10.1016/j.jairtraman.2015.03.001.

There was a significant difference between the means for "Convenience" comparing the groups of passengers that arrived at the airport earlier and closer to flight departure time (by ANOVA, at 0.01 level). Moreover, a model estimated with a sample limited to passengers who arrived earlier than $3 \mathrm{~h}$ before departure returned no significance for "Convenience". Correia et al. (2008a) found a similar result using the attribute concessions with a sample from the same airport.

Regarding the nature as satisfier or dissatisfier, restaurants and stores at the airport may be considered dissatisfiers for passenger satisfaction (Bogicevic et al., 2013), which mean that an increase in their quality should not have greater impact in creating satisfaction, but a decrease should create dissatisfaction (Johnston, 1995).

Therefore, it seems that the "Convenience" dimension (formed by the attributes Food facilities, Stores, Bank/ATM/Exchange, and Courtesy and helpfulness of staff) presented mainly a dissatisfier effect on overall satisfaction. Moreover, the amount of time the passenger spends at the airport seems to be determinant for his/her perception about this dimension.

\subsubsection{Magnitude of the effects}

In the model, the exponentiated coefficient (see two last columns of Table 2) offers an idea of the magnitude of the marginal effects on the probability of observing higher categories for overall satisfaction against lower categories. 
Bezerra, G.C.L., \& Gomes, C.F. (2015) "The effects of service quality dimensions and passenger characteristics on passenger's overall satisfaction with an airport", Journal of Air Transport Management, 44-45, pp. 7781, http://dx.doi.org/10.1016/j.jairtraman.2015.03.001.

For instance, the increase by one point on the scale for "Ambience" (which is the dimension with the highest effect) would increase the odds in $736.5 \% . \underline{2}$ In fact, passengers' perception of the ambient conditions has been recognized as important factor for ASQ (Bogicevic et al., 2013; Fodness and Murray, 2007; Jeon and Kim, 2012; Park and Jung, 2011).

The dimension with the second highest marginal effect was "Prices", with an increase of $88.5 \%$ on the odds. This finding suggests that passengers are sensitive to the prices for food and other goods at the airport stores. In fact, that was the dimension with the lowest mean in the study.

The interpretation is the same for the other dimensions, according to the results presented in Table 2.

Regarding the passenger characteristics, since they are categorical variables the interpretation must compare two categories in sequence. According to the results, a passenger who arrived at the airport with more than $3 \mathrm{~h}$ to flight departure time is $20.8 \%$ more likely to assign a higher rate for overall satisfaction when compared to another passenger arriving with more than $2 \mathrm{~h}$ but less than $3 \mathrm{~h}$ to flight departure time, for instance.

Likewise, a passenger who travelled 3 to 5 times in the last year is $15.7 \%$ less likely to assign a higher rate for overall satisfaction with the airport when compared to a less frequent flyer that travelled no more than 2 times, for instance. 
Bezerra, G.C.L., \& Gomes, C.F. (2015) "The effects of service quality dimensions and passenger characteristics on passenger's overall satisfaction with an airport", Journal of Air Transport Management, 44-45, pp. 7781, http://dx.doi.org/10.1016/j.jairtraman.2015.03.001.

By replacing the values for a particular passenger on the independent variables in the estimated equation, one can compare probabilities in terms of the odds among different passenger profiles.

\section{CONCLUDING REMARKS}

The focus of research and practice in Airport Service Quality (ASQ) has been mainly on the service-attribute level and the effects of different service quality dimensions on passenger satisfaction have not been fully researched. Therefore, this study is a small piece of contribution for the development of a broader understanding of ASQ dimensions from a passenger perspective.

The seven dimensions extracted from a set of attributes widely used by the airport industry provided a representative framework of how passengers evaluate ASQ. This set of dimensions represents a valuable alternative for a more parsimonious multivariate analysis, instead of considering several attributes individually.

Although the sample used is specific to a main Brazilian airport, this study illustrates how the probabilistic approach may be useful for stressing the direction and magnitude of the effects of service quality dimensions and passenger characteristics on the probability that a passenger presents higher levels of overall satisfaction with an airport. Probabilistic models may be particularly useful to explore differences among passenger profiles, as discussed above. 
Bezerra, G.C.L., \& Gomes, C.F. (2015) "The effects of service quality dimensions and passenger characteristics on passenger's overall satisfaction with an airport", Journal of Air Transport Management, 44-45, pp. 7781, http://dx.doi.org/10.1016/j.jairtraman.2015.03.001.

Since the perceived service quality is subjective and context dependent (Brady and Cronin, 2001; Wilson et al., 2012), the more specific findings from this study need to be interpreted within the particular airport context and should not be generalized to other service environment.

Regarding future works, since airliners and airports services share a significant area of overlap, airline-related services with impact on ASQ should be more investigated (e.g. availability and frequency of flights, flight cancellation, etc.). Furthermore, although the set of attributes used in this study has proved to be valid and suitable, ASQ dimensions should be built from a deeper investigation on passenger behaviour and expectations, including differences among groups of passengers regarding their profiles and motivation. Those aspects seem to be major challenges for the research on Airport Service Quality.

\section{REFERENCES}

ACl, 2012. Guide to Airport Performance Measures. Quebec. Retrieved from. http://www.acilac.aero/Media/aci/downloads/ACI_APM_Guidebook_2_2012.pdf.

ACI, 2013. Airport-Service-Quality/About-ASQ. Airports Council International.Retrieved October 29, 2013, from. http://www.aci.aero/Airport-Service-Quality/About-ASQ.

Akinci, S., Kaynak, E., Atilgan, E., Aksoy, S., 2007. Where does the logistic regression analysis stand in marketing literature?: a comparison of the market positioning of prominent marketing journals. Eur. J. Mark. 41 (5/6), 537e567. http://dx.doi.org/10.1108/03090560710737598. 
Bezerra, G.C.L., \& Gomes, C.F. (2015) "The effects of service quality dimensions and passenger characteristics on passenger's overall satisfaction with an airport", Journal of Air Transport Management, 44-45, pp. 77-

81, http://dx.doi.org/10.1016/j.jairtraman.2015.03.001.

Bandeira, M.C.G.S.P., Borille, G.M.R., Maia, M.C.D., Moser, R.F., 2014. Key indicators that affect the perception of service quality in critical airport areas of passenger boarding. J. Transp. Lit. 8 (4), 7e36.

Bogicevic, V., Yang, W., Bilgihan, A., Bujisic, M., 2013. Airport service quality drivers of passenger satisfaction. Tour. Rev. 68 (4), 3e18. http://dx.doi.org/10.1108/TR-09-20130047.

Brady, M.K., Cronin, J.J.J., 2001. Some new thoughts on conceptualizing perceived service quality: a hierarchical approach. J. Mark. 65, 34e49.

Carstens, S., Heyns, G., 2012. The influence of passenger demographics on airport attribute evaluation. J. Transp. Supply Chain Manag. 6 (1), 55e72.

Caves, R.E., Pickard, C.D., 2000. The satisfaction of human needs in airport passenger terminals. Transport 147 (1), 9e15.

Correia, A.R., Wirasinghe, S.C., de Barros, A.G., 2008a. A global index for level of service evaluation at airport passenger terminals. Transp. Res. Part E: Logist. Transp. Rev. 44, 607e620. http://dx.doi.org/10.1016/j.tre.2007.05.009.

Correia, A.R., Wirasinghe, S.C., de Barros, A.G., 2008b. Overall level of service measures for airport passenger terminals. Transp. Res. Part A: Policy Pract. 42(2), 330e346. http://dx.doi.org/10.1016/j.tra.2007.10.009.

Crawford, G., Melewar, T.C., 2003. The importance of impulse purchasing behavior in the international airport environment. J. Consum. Behav. 3 (1), 85e98.

Eboli, L., Mazzulla, G., 2009. An ordinal logistic regression model for analyzing airport passenger satisfaction. EuroMed J. Bus. 4 (1), 40e57.

Falk, T., Hammerschmidt, M., Schepers, J.J.L., 2010. The service quality-satisfaction link revisited: exploring asymmetries and dynamics. J. Acad. Mark. Sci. 38, 288e302. http://dx.doi.org/10.1007/s11747-009-0152-2.

Fodness, D., Murray, B., 2007. Passengers' expectations of airport service quality. J. Serv. Mark. 21 (7), 492e506. http://dx.doi.org/10.1108/08876040710824852.

George, B.P., Henthorne, T.L., Panko, T.R., 2013. ASQual: measuring tourist perceived service quality in an airport setting. Int. J. Bus. Excell. 6 (5), 526e536. 
Bezerra, G.C.L., \& Gomes, C.F. (2015) "The effects of service quality dimensions and passenger characteristics on passenger's overall satisfaction with an airport", Journal of Air Transport Management, 44-45, pp. 77-

81, http://dx.doi.org/10.1016/j.jairtraman.2015.03.001.

Gkritza, K., Niemeier, D., Mannering, F., 2006. Airport security screening and changing passenger satisfaction: an exploratory assessment. J. Air Transp. Manag. 12 (5), 213e219. http://dx.doi.org/10.1016/j.jairtraman.2006.03.001.

Gujarati, D.N., Porter, D.C., 2011. Econometria Básica, fifth ed. McGraw Hill-Bookman, Porto Alegre.

Hair, J.F., Black, W.C., Babin, B.J., Anderson, R.E., 2009. Multivariate Data Analysis. Prentice Hall, New Jersey.

Hazel, R.A., Blais, J.D., Browne, T.J., Benzon, D.M., 2011. ACRP Report 19A: Resource Guide to Airport Performance Indicators. Washington.

IATA, 2012. Iata Global Passenger Survey Highlights. International Air Transportation Association.

Jeon, S., Kim, M.S., 2012. The effect of the servicescapeon customers' behavioral intentions in an international airport service environment. Serv. Bus. 6 (3), $279 e 295$.

Johnston, R., 1995. The determinants of service quality: satisfiers and dissatisfiers. J. Serv. Ind. Manag. 6 (5), 53e71.

Omar, O., Kent, A., 2001. International airport influences on impulsive shopping: trait and normative approach. Int. J. Retail Distrib. 29 (5), 226.

Pakdil, F., Aydın, €O., 2007. Expectations and perceptions in airline services: an analysis using weighted SERVQUAL scores. J. Air Transp. Manag. 13 (4), 229e237. http://dx.doi.org/10.1016/j.jairtraman.2007.04.001.

Park, J.W., 2010. The effect of frequent flyer programs: a case study of the Korean airline industry. J. Air Transp. Manag. 16 (5), 287e288.

Park, J.W., Jung, S.Y., 2011. Transfer passengers' perceptions of airport service quality: a case study of Incheon International Airport. Int. Bus. Res. 4 (3), 75e82. http://dx.doi.org/10.5539/ibr.v4n3p75.

SAC, 2014. Relat_orio geral dos indicadores de desempenho operacional de aeroportos, pp. 1 e85 (Brasília).

Seyanont, A., 2012. Passengers' perspective toward airport service quality at Suvarnabhumi International Airport. J. Soc. Transp. Traffic Stud. 3 (3), 32e41. 
Bezerra, G.C.L., \& Gomes, C.F. (2015) "The effects of service quality dimensions and passenger characteristics on passenger's overall satisfaction with an airport", Journal of Air Transport Management, 44-45, pp. 77-

81, http://dx.doi.org/10.1016/j.jairtraman.2015.03.001.

Thrane, C., 2005. How to present results from logistic regression analysis in hospitality and tourism research. Tour. Hosp. Res. 5 (4), 295 e305. http://dx.doi.org/10.1057/palgrave.thr.6040029.

Wilson, A., Zeithaml, V.A., Bitner, M.J., Gremler, D.D., 2012. Services Marketing: Integrating Customer Focus across the Firm, second ed. McGraw-Hill, Berkshire.

Yeh, C.-H., Kuo, Y.-L., 2003. Evaluating passenger services of Asia-Pacific international airports. Transp. Res. Part E: Logist. Transp. Rev. 39 (1), 35e48. http://dx.doi.org/10.1016/S13665545(02)00017-0.

Zidarova, E.D., Zografos, K.G., 2011. Measuring quality of service in airport passenger terminals. J. Transp. Res. Board 2214, 69e76. 
Bezerra, G.C.L., \& Gomes, C.F. (2015) "The effects of service quality dimensions and passenger characteristics on passenger's overall satisfaction with an airport", Journal of Air Transport Management, 44-45, pp. 7781, http://dx.doi.org/10.1016/j.jairtraman.2015.03.001.

\section{APPENDIX A}

TABLE A.1. SAMPLE CHARACTERISTICS.

\begin{tabular}{|c|c|c|}
\hline Nationality & Freq. & $\%$ \\
\hline Brazilian & 1,433 & $91.4 \%$ \\
\hline Other & 135 & $8.6 \%$ \\
\hline Total & 1,568 & $100 \%$ \\
\hline \multicolumn{3}{|l|}{ Gender } \\
\hline Male & 880 & $56.1 \%$ \\
\hline Female & 688 & $43.9 \%$ \\
\hline Total & 1,568 & $100 \%$ \\
\hline \multicolumn{3}{|l|}{ Passenger with reduced mobility (PRM) } \\
\hline No & 1,546 & $98.6 \%$ \\
\hline Yes & 22 & $1.4 \%$ \\
\hline Total & 1,568 & $100 \%$ \\
\hline \multicolumn{3}{|l|}{ Trip purpose } \\
\hline Non business (Includes leisure and other purposes) & 863 & $55.0 \%$ \\
\hline Business & 705 & $45.0 \%$ \\
\hline Total & 1,568 & $100 \%$ \\
\hline \multicolumn{3}{|l|}{ Earliness of arrival } \\
\hline Less than 2 hours & 197 & $12.6 \%$ \\
\hline Equal or more than 2 hours and less than 3 hours & 651 & $41.5 \%$ \\
\hline Equal or more than 3 hours & 720 & $45.9 \%$ \\
\hline Total & 1,568 & $100 \%$ \\
\hline \multicolumn{3}{|l|}{ Travel frequency (year) } \\
\hline 0 to 2 trips & 349 & $22.3 \%$ \\
\hline 3 to 5 trips & 726 & $46.3 \%$ \\
\hline$>5$ trips & 493 & $31.4 \%$ \\
\hline Total & 1,568 & $100 \%$ \\
\hline
\end{tabular}




\section{APPENDIX B. ORDINAL LOGISTIC REGRESSION SPECIFICATION.3}

$$
\begin{aligned}
& \ln \frac{\operatorname{Pr}\left(Y_{i} \leq j \mid X\right)}{\operatorname{Pr}\left(Y_{i}>j \mid X\right)}=\ln e^{a_{j}-X b}=a_{j}-b_{1} \text { Chk }_{i}-b_{2} \text { Sec }_{i}-b_{3} \text { Con }_{i}-b_{4} \text { Amb }_{i}-b_{5} \text { Bas }_{i} \\
& -b_{6} \text { Mob }_{i}-b_{7} \text { Prc }_{i}-b_{8} \text { Nat }_{i}-b_{9} \text { Gen }_{i}-b_{10} \text { Prm }_{i}-b_{11} \text { Trp }_{i}-b_{12} \text { Arr }_{i}-b_{13} \text { Frq }_{i}-u_{i}
\end{aligned}
$$

Where:

In = natural logarithm.

$\mathrm{Pr}$ - probability

$Y_{i}$ - category for overall satisfaction with the airport (from 1 to 5 )

$j=1,2,3$, and 4 (number of categories of the dependent variable minus one)

$X=$ vector of the explanatory variables

$\ln \left[\operatorname{Pr}\left(Y_{i} \leq j \mid X\right) / \operatorname{Pr}\left(Y_{i}>j \mid X\right)\right]=$ Logit

$a$ - constant (four values are calculated)

$b$ - regression coefficients

$u_{i}$ - error

$C h k_{i}$ - score for Check-in on the ith observation

$\mathrm{Sec}_{i}$ - score for Security on the ith observation

$\mathrm{Con}_{i}$ - score for Convenience on the ith observation

$A m b_{i}$ - score for Ambience on the $i$ th observation

$B a s_{i}$ - score for Basic facilities on the ith observation

$M o b_{i}$ - score for Mobility on the ith observation

$\mathrm{PrC}_{i}$ - score for Price on the ith observation

$\mathrm{Nat}_{i}$ - category for Nationality on the ith observation

$\mathrm{Gen}_{i}$ - category for Gender on the ith observation

$\mathrm{Prm}_{i}$ - category for Passenger with reduced mobility on the ith observation

$\mathrm{Trp}_{i}$ - category for Trip purpose on the ith observation

$\mathrm{Arr}_{i}$ - category for Earliness of arrival on the ith observation

$\mathrm{Frq}_{i}-$ category for Travel frequency on the ith observation 


\section{TABLE 1 - SERVICE QUALITY DIMENSIONS AND EFA RESULTS}

\begin{tabular}{|c|c|c|c|c|c|c|c|c|}
\hline $\begin{array}{l}\text { DIMENSIONS } \\
\text { (Cronbach's Alpha) }\end{array}$ & $\begin{array}{c}\text { CHK } \\
(0.797)\end{array}$ & $\begin{array}{c}\text { SEC } \\
(0.773)\end{array}$ & $\begin{array}{c}\text { CON } \\
(0.717)\end{array}$ & $\begin{array}{c}\text { AMB } \\
(0.798)\end{array}$ & $\begin{array}{c}\text { BAS } \\
(0.792)\end{array}$ & $\begin{array}{c}\text { MOB } \\
(0.730)\end{array}$ & $\begin{array}{c}\text { PRC } \\
(0.710)\end{array}$ & $\begin{array}{c}\text { Communa } \\
\text { lities }\end{array}$ \\
\hline \multicolumn{9}{|l|}{ Check-in (CHK) } \\
\hline Wait time at check-in & 0.634 & & & & & & & 0.629 \\
\hline Check-in process efficiency & 0.841 & & & & & & & 0.810 \\
\hline Courtesy and helpfulness of check-in staff & 0.791 & & & & & & & 0.748 \\
\hline Availability of luggage carts & 0.654 & & & & & & & 0.532 \\
\hline \multicolumn{9}{|l|}{ Security (SEC) } \\
\hline Courtesy and helpfulness of security staff & & 0.711 & & & & & & 0.638 \\
\hline Thoroughness of security screening & & 0.761 & & & & & & 0.661 \\
\hline Wait-time at security check-points & & 0.737 & & & & & & 0.654 \\
\hline Feeling of being safe and secure & & 0.644 & & & & & & 0.540 \\
\hline \multicolumn{9}{|l|}{ Convenience (CON) } \\
\hline Availability and quality of food facilities & & & 0.775 & & & & & 0.658 \\
\hline Availability of Banks/ATM/Exchange & & & 0.733 & & & & & 0.632 \\
\hline Availability and quality of stores & & & 0.668 & & & & & 0.601 \\
\hline Courtesy and helpfulness of airport staff & & & 0.531 & & & & & 0.501 \\
\hline \multicolumn{9}{|l|}{ Ambience (AMB) } \\
\hline Thermal comfort & & & & 0.812 & & & & 0.778 \\
\hline Acoustic comfort & & & & 0.827 & & & & 0.786 \\
\hline Cleanliness of airport facilities & & & & 0.579 & & & & 0.606 \\
\hline \multicolumn{9}{|l|}{ Basic Facilities (BAS) } \\
\hline Departure lounge comfort & & & & & 0.622 & & & 0.660 \\
\hline Availability of washroom/toilets & & & & & 0.833 & & & 0.775 \\
\hline Cleanliness of washroom/toilets & & & & & 0.834 & & & 0.792 \\
\hline \multicolumn{9}{|l|}{ Mobility (MOB) } \\
\hline Wayfinding & & & & & & 0.696 & & 0.616 \\
\hline Flight information & & & & & & 0.743 & & 0.681 \\
\hline Walking distance inside terminal & & & & & & 0.699 & & 0.633 \\
\hline \multicolumn{9}{|l|}{ Prices (PRC) } \\
\hline Prices at food facilities & & & & & & & 0.799 & 0.727 \\
\hline Prices at stores & & & & & & & 0.842 & 0.784 \\
\hline Eigenvalues & 2.66 & 2,58 & 2.24 & 2.13 & 2.07 & 2.03 & 1.73 & \\
\hline$\%$ of variance & 11.57 & 11.22 & 9.72 & 9.28 & 9.02 & 8.83 & 7.51 & \\
\hline$\%$ cumulative & 11.57 & 22.79 & 32.51 & 41.79 & 50.81 & 59.63 & 67.15 & \\
\hline
\end{tabular}


Bezerra, G.C.L., \& Gomes, C.F. (2015) "The effects of service quality dimensions and passenger characteristics on passenger's overall satisfaction with an airport", Journal of Air Transport Management, 44-45, pp. 7781, http://dx.doi.org/10.1016/j.jairtraman.2015.03.001.

\section{TABLE 2 - PARAMETER ESTIMATION}

\begin{tabular}{|l|lrrrrrr|}
\hline \multicolumn{1}{|c}{} & & Estimate & $\begin{array}{c}\text { Std. } \\
\text { Error }\end{array}$ & Wald & Sig. & Exp(B) & $\begin{array}{c}\text { Odds- } \\
\text { ratio \% }\end{array}$ \\
\hline \multirow{5}{*}{ Threshold } & [overall_satisfaction = 1] & 6.291 & .480 & 171.746 & 0.000 & - & - \\
& [overall_satisfaction = 2] & 9.475 & .506 & 351.026 & 0.000 & - & - \\
& [overall_satisfaction = 3] & 12.460 & .552 & 509.941 & 0.000 & - & - \\
& [overall_satisfaction = 4] & 16.167 & .611 & 699.422 & 0.000 & - & - \\
\hline \multirow{5}{*}{ Location } & Check-in & 0.241 & .077 & 9.85 & 0.002 & 1.273 & 27.3 \\
& Security & 0.310 & .086 & 13.08 & 0.000 & 1.363 & 36.3 \\
& Convenience & -0.276 & .080 & 11.94 & 0.001 & 0.759 & -24.1 \\
& Ambience & 2.124 & .102 & 430.44 & 0.000 & 8.365 & 736.5 \\
& Basic facilities & 0.592 & .075 & 62.14 & 0.000 & 1.808 & 80.8 \\
& Prices & 0.634 & .058 & 118.55 & 0.000 & 1.885 & 88.5 \\
& Earliness of arrival & 0.189 & .079 & 5.73 & 0.017 & 1.208 & 20.8 \\
& Travel frequency & -0.171 & .073 & 5.47 & 0.019 & 0.843 & -15.7 \\
\hline
\end{tabular}

Likelihood-ratio $=x^{2}(8): 1348.43, \mathrm{p}$-value $<0.01 ; R^{2}$ Cox \& Snell $=0.577 ; R^{2}$ Nagelkerke $=0.621$ and $R^{2}$ McFadden $=0.325$; Count $R^{2}=60.1 \%$. 